\title{
BMJ Open The effects of designation and volume of neonatal care on mortality and morbidity outcomes of very preterm infants in England: retrospective population-based cohort study
}

\section{S I Watson, ${ }^{1}$ W Arulampalam, ${ }^{2}$ S Petrou, ${ }^{1}$ N Marlow, ${ }^{3}$ A S Morgan, ${ }^{3}$ E S Draper, ${ }^{4}$ $S$ Santhakumaran, ${ }^{5} \mathrm{~N}$ Modi, ${ }^{5}$ On behalf of the Neonatal Data Analysis Unit and the NESCOP Group}

To cite: Watson SI,

Arulampalam W, Petrou S, et al. The effects of designation and volume of neonatal care on mortality and morbidity outcomes of very preterm infants in England: retrospective populationbased cohort study. BMJ Open 2014;4:e004856. doi:10.1136/bmjopen-2014004856

- Prepublication history and additional material is available. To view please visit the journal (http://dx.doi.org/ 10.1136/bmjopen-2014004856).

Received 14 January 2014 Revised 15 April 2014 Accepted 14 May 2014

CrossMark

For numbered affiliations see end of article.

Correspondence to

S I Watson;

s.i.watson@warwick.ac.uk

\section{ABSTRACT}

Objective: To examine the effects of designation and volume of neonatal care at the hospital of birth on mortality and morbidity outcomes in very preterm infants in a managed clinical network setting.

Design: A retrospective, population-based analysis of operational clinical data using adjusted logistic regression and instrumental variables (IV) analyses.

Setting: 165 National Health Service neonatal units in England contributing data to the National Neonatal Research Database at the Neonatal Data Analysis Unit and participating in the Neonatal Economic, Staffing and Clinical Outcomes Project.

Participants: 20554 infants born at $<33$ weeks completed gestation (17 995 born at 27-32 weeks; 2559 born at $<27$ weeks), admitted to neonatal care and either discharged or died, over the period 1 January 2009-31 December 2011.

Intervention: Tertiary designation or high-volume neonatal care at the hospital of birth.

Outcomes: Neonatal mortality, any in-hospital mortality, surgery for necrotising enterocolitis, surgery for retinopathy of prematurity, bronchopulmonary dysplasia and postmenstrual age at discharge.

Results: Infants born at $<33$ weeks gestation and admitted to a high-volume neonatal unit at the hospital of birth were at reduced odds of neonatal mortality (IV regression odds ratio (OR) $0.70,95 \% \mathrm{Cl} 0.53$ to 0.92 ) and any in-hospital mortality (IV regression OR 0.68 , $95 \% \mathrm{Cl} 0.54$ to 0.85 ). The effect of volume on any inhospital mortality was most acute among infants born at $<27$ weeks gestation (IV regression OR $0.51,95 \% \mathrm{CI}$ 0.33 to 0.79 ). A negative association between tertiarylevel unit designation and mortality was also observed with adjusted logistic regression for infants born at $<27$ weeks gestation.

Conclusions: High-volume neonatal care provided at the hospital of birth may protect against in-hospital mortality in very preterm infants. Future developments of neonatal services should promote delivery of very preterm infants at hospitals with high-volume neonatal units.

\section{Strengths and limitations of this study}

- A national dataset consisting of the electronic patient records of a large majority of admissions to neonatal specialist care in England.

- The analysis takes into account observed and unobserved confounding.

- A weakness is that the analysis is unable to disentangle the effects of the neonatal unit at the place of birth from subsequent transfers to other neonatal units.

\section{INTRODUCTION}

Intense debate has revolved around the optimal organisation of neonatal critical care services. Numerous studies have suggested that the intensity and volume of neonatal care at the hospital of birth is negatively correlated with adverse clinical outcomes, including mortality. ${ }^{1-11}$ This has contributed to calls for centralisation of neonatal services and the closure of smaller neonatal units. $^{2} 1112$

Following a review by the Department of Health in 2003, perinatal centres in England were reorganised into managed clinical networks (MCN). ${ }^{13}$ MCNs provide some of the benefits of centralisation, but also strive to maintain equity and ease of access to services by keeping lower care level and lower volume neonatal units open, with provision for transfer to higher care level or higher volume units, if required. ${ }^{13}$ Particular emphasis is placed on the importance of transferring women at risk of extremely preterm labour to tertiary centres before delivery. Consequently, most networks aim to transfer women at high risk of delivery at $<27$ weeks gestation. We have previously shown that, 
since the formation of MCNs, the proportion of lowgestational age infants born in hospitals with higher designation neonatal units and their transfer rate between hospitals has increased significantly; however, it remains unclear what effect this has had on clinical outcomes. ${ }^{14}$

Studies that have examined the effects of neonatal unit designation or volume of neonatal care provided at the hospital of birth have shown that low designation level or volume is associated with increased rates of mortality, ${ }^{1-10}$ decreased infection rate, ${ }^{7}$ increased severe periventricular haemorrhage ${ }^{11}$ and increased bronchopulmonary dysplasia. ${ }^{7}$ However, these studies were almost exclusively conducted in the USA where there is greater variability in neonatal unit volume-the highest volume units in the USA are typically much larger than equivalent units in England-and there are no formal arrangements for MCNs. Results from similar studies using data from the UK are limited and based on data from 1998 to 1999 , prior to the formation of MCNs. ${ }^{15} 16$ We are not aware of any studies that have examined infant outcomes for neonatal specialist services in MCNs in relation to unit designation or volume. In addition, organisation of neonatal care differs between countries potentially affecting the generalisability of results from these systems; for example, in Germany neonatal services are markedly deregionalised whereas in Finland and Portugal there is a high degree of regionalisation. ${ }^{17}$

Our aim in this study was to examine the effects of designation and volume of neonatal care provided at the hospital of birth on mortality and morbidity outcomes. We assess whether organisational factors remain determinants of clinical outcomes despite the goals of neonatal reorganisation that sought to ensure that vulnerable infants are not disadvantaged by their place of birth.

\section{METHODS}

\section{Data source and study population}

For the purpose of this empirical investigation, we extracted data from the National Neonatal Research Database (NNRD) for neonatal units participating in the Neonatal Economic, Staffing and Clinical Outcomes Project (NESCOP). The NNRD is held by the Neonatal Data Analysis Unit (NDAU), Imperial College, London, and was created from patient-level electronic records of all infants admitted to 168 of 173 neonatal units in England. NESCOP included 165 centres providing perinatal care. On behalf of NESCOP, the Medical Research Council (MRC) EPICure studies carried out the Unit Profile Survey (UPS) during 2011, comprising a survey of English hospitals that provided onsite obstetric and neonatal services. We extracted records from the NNRD of all infants born in participating centres at $\leq 32^{+6}$ weeks $^{+ \text {days }}$ gestation, admitted over the period 1 January 2009-31 December 2011, and who were discharged or died over the same period. We excluded infants who only received transitional care $(\mathrm{n}=5)$, which was defined according to English Department of Health's Healthcare Resource Group (HRG4) code 'XA04Z'. ${ }^{18}$ Gestational age was determined by ultrasound scan.

\section{Outcomes}

We derived the following outcomes from the extracted data for use in the analyses: 28-day (neonatal) mortality, any in-hospital mortality, surgery for necrotising enterocolitis, treatment for retinopathy of prematurity (ROP) and bronchopulmonary dysplasia (BPD). We defined BPD as the requirement of supplementary oxygen for at least 28 days and at 36 weeks postmenstrual age (PMA). ${ }^{19}$ We also examined PMA at discharge as a marker of length of stay; this was defined as the gestational age at birth plus the length of stay at final discharge from any neonatal unit or death. We defined the outcome to be one if the PMA at discharge was greater than 40 weeks and zero otherwise.

\section{Covariates}

To determine appropriate covariates, we reviewed previous prediction models for very preterm infants ${ }^{20}$ and selected variables that (1) were significant predictors of adverse sequelae, (2) were available in our dataset and of high quality and (3) not confounded by the provision of neonatal care. The variables we included were: gestational age at birth, gestational age squared, birthweight z-score (birth weight standardised by gestational age week) and the following indicators: whether the mother received a full or partial course of antenatal steroids, sex, infant year of birth and whether or not the mother came from an area within the lowest decile of the Index of Multiple Deprivation 2007 score. ${ }^{21}$

\section{Statistical methods}

We conducted two separate sets of analyses based on whether or not infants were admitted to a neonatal unit at the hospital of birth designated as: (1) a tertiary centre $^{22}$ or (2) high volume. For the latter, we defined volume according to the annual number of care days at any level of care provided to very preterm infants $\left(\leq 32^{+6}\right.$ weeks gestation). A 'high-volume' unit was defined as one whose volume was in the top quartile of all neonatal units in the sample. 'High volume' was determined by quartile rather than an absolute care day threshold to facilitate comparison with other measures of volume in the sensitivity analyses. A previous study that examined organisational characteristics of neonatal units also categorised volume using quartiles. ${ }^{17}$ Dichotomising by upper quartile divided the infants between high-volume and low-volume units in approximately the same proportion as between tertiary-level and non-tertiary-level units. To aid comparison with other studies, in particular from the USA, and as a robustness check, 'high volume' was also defined as 100 very low birthweight (VLBW; $<1500 \mathrm{~g}$ ) admissions of infants born in the same hospital per annum. 
We first conducted an unadjusted comparison of clinical characteristics and outcomes of infants by unit characteristics. Second, we estimated an adjusted model and finally, we conducted an adjusted comparison using an instrumental variables methodology to account for unobserved confounding. In the absence of a randomised control trial, instrumental variables methodology acts as an ex post randomisation and enables us to estimate the 'causal effects' of designation and volume of neonatal care provided at the hospital of birth. The methodology involves the use of a variable called an 'instrument' which, in this context, needs to fulfil two criteria: (1) it should be strongly correlated with the characteristics of the neonatal unit at the hospital of birth and (2) it should be uncorrelated with the outcomes of interest conditional on observed covariates and therefore uncorrelated with unobserved confounders.

For the instruments, we used indicators for the designated level of care of the nearest neonatal unit to the mother's residence, an indicator for whether it had surgical facilities, an indicator for whether it was high volume, the distance to the nearest neonatal unit and the interactions of either the level of care indicators or high-volume indicator with distance, giving nine instruments in total. Straight line distance was calculated from the population-weighted centre of the mother's lower super output area to each hospital. ${ }^{23}$

These instrumental variables fulfil condition (1) if infants are more likely to be born in the hospital closest to the mother's residence. They will also fulfil condition (2) if the location of the mother's residence is uncorrelated with an infant's unobserved clinical risk. We tested for a difference in observed characteristics by level and volume of the nearest neonatal unit. However, tertiarylevel and high-volume units are more likely to be in urban areas that are socioeconomically deprived so we may expect to see more preterm and low birthweight infants being born in these areas. ${ }^{24}$ We therefore also controlled for local deprivation when testing for a difference in means by nearest neonatal unit characteristics by estimating a linear regression of the observed variable of interest on the nearest neonatal unit characteristic and deprivation indicator, and using an F-test to test the coefficient on the nearest neonatal unit characteristic variable.

As the outcomes are all binary logistic regression was used. In order to employ instrumental variables estimation in this framework, two-stage residual inclusion (2SRI) was used. ${ }^{25}$ The 2SRI method is explained in online supplementary appendix A. The SEs were adjusted for clustering within units.

Our baseline analyses examined infants born at $\leq 32^{+6}$ weeks gestation. We then conducted analyses on subsets of infants born at $\leq 26^{+6}$ weeks gestation or at $27^{+0}-32^{+6}$ weeks gestation; $\leq 26^{+6}$ weeks gestation is the cut-off used by perinatal networks for prioritising interunit transfers. 'Statistical significance', where discussed, refers to a $5 \%$ significance level in all cases.
Missing data and sensitivity analyses

Infants with missing outcomes data were excluded from the analyses, while those with missing covariate data were assigned a zero in the case of binary indicators. There were no infants with missing continuous covariates. We excluded all infants with any missing data as a further sensitivity analysis.

Separate sensitivity analyses, using our preferred method of instrumental variables logistic regression, also explored the effects of: (1) including unit random effects in the statistical models; (2) removing infants who died from analyses of the morbidity and PMA at discharge outcomes and defining a new outcome of any in-hospital mortality and/or BPD to account for possible bias caused by infants dying prior to experiencing the morbidity outcome; (3) redefining high volume as the top $25 \%$ of units in terms of intensive care days provided to $\leq 32^{+6}$ gestational week infants; (4) redefining high volume as the top $25 \%$ of units in terms of number of $\leq 32^{+6}$ gestational week infants cared for and (5) redefining high volume as at least 100 VLBW infants born in and admitted to the neonatal unit in the hospital per annum.

All analyses were carried out with R V.2.14.2 and Stata V.11.

\section{RESULTS}

In total, data for 20554 infants born at $\leq 32^{+6}$ weeks gestation over the study period and admitted to a neonatal unit at the hospital of birth were extracted from the NNRD, 2559 of whom were born at $\leq 26^{+6}$ weeks gestation. Table 1 provides descriptive statistics of the samples analysed.

In the sample, $9466(46.1 \%)$ infants were born in hospitals with a tertiary-level neonatal unit and 9541 (46.4\%) were born in hospitals with a high-volume neonatal unit. The cut-off for high volume was approximately 3480 annual care days for infants born at $\leq 32^{+6}$ weeks gestation in each hospital. The total sample of 20554 infants were born in 165 different hospitals, 44 $(26.7 \%)$ of which had level 3 neonatal units, 81 (49\%) level 2 neonatal units and $39(23.6 \%)$ level 1 neonatal units. There were $39(23.6 \%)$ neonatal units classified as high volume, $30(78 \%)$ of which were designated level 3 units; consequently, 14 of the $44(31.8 \%)$ level 3 designated units were not classified as high volume. Among the 20554 infants, 1892 (9.2\%) were born in hospitals with neonatal units that were classified as high volume but not tertiary level and $1817(8.8 \%)$ were born in hospitals with neonatal units classified as tertiary level but not high volume.

\section{'Standard' adjusted results}

Table 2 presents the estimated adjusted ORs associated with admission to either tertiary or high-volume neonatal care at the hospital of birth. 
Table 1 Descriptive statistics for preterm infants born $\leq 32^{+6}$ weeks gestation by neonatal unit characteristic at the hospital of birth

\begin{tabular}{|c|c|c|c|c|c|c|}
\hline & \multicolumn{3}{|c|}{ Designation of unit } & \multicolumn{3}{|l|}{ Volume of unit* } \\
\hline & $\begin{array}{l}\text { Tertiary-level } \\
\text { unit }\end{array}$ & $\begin{array}{l}\text { Non-tertiary- } \\
\text { level unit }\end{array}$ & p Value & $\begin{array}{l}\text { High- } \\
\text { volume unit }\end{array}$ & $\begin{array}{l}\text { Non-high- } \\
\text { volume unit }\end{array}$ & p Valuet \\
\hline n (\%) & $9466(46.1)$ & $11088(54.0)$ & & $9541(46.4)$ & $11013(53.6)$ & \\
\hline Gestation (weeks), mean (SD) & $29.2(2.5)$ & $30.0(2.1)$ & $<0.001$ & $29.3(2.5)$ & $29.9(2.2)$ & $<0.001$ \\
\hline Birth weight $(\mathrm{g})$, mean (SD) & $1313.9(438.7)$ & $1451.9(404.5)$ & $<0.001$ & $1326.6(436.7)$ & $1441.8(409.4)$ & $<0.001$ \\
\hline $\begin{array}{l}\text { Received full or partial course of } \\
\text { antenatal steroids }\end{array}$ & $6394(67.6)$ & $7262(65.5)$ & 0.002 & $6330(66.4)$ & $7326(66.5)$ & 0.790 \\
\hline Deprivation score bottom $10 \%$ & $2020(21.4)$ & $1342(12.1)$ & $<0.001$ & $1730(18.1)$ & $1632(14.8)$ & $<0.001$ \\
\hline Male & $5048(53.3)$ & $5397(53.4)$ & 0.756 & $5093(53.4)$ & $5892(53.5)$ & 0.863 \\
\hline Neonatal mortality & $423(4.5)$ & $366(3.3)$ & $<0.001$ & $394(4.1)$ & $395(3.6)$ & 0.043 \\
\hline Any in-hospital mortality & $569(6.0)$ & $425(3.8)$ & $<0.001$ & $527(5.5)$ & 467 (4.2) & $<0.001$ \\
\hline BPD $\ddagger$ & 3695 (39.0) & $2856(25.8)$ & $<0.001$ & 3548 (37.2) & 3003 (27.3) & $<0.001$ \\
\hline Treatment for ROP & $226(2.4)$ & $107(1.0)$ & $<0.001$ & $195(2.0)$ & $138(1.3)$ & $<0.001$ \\
\hline Surgery for NEC & $167(1.8)$ & $123(1.1)$ & $<0.001$ & $163(1.7)$ & $127(1.2)$ & 0.001 \\
\hline PMA $\S$ at discharge $>40^{+0}$ weeks & $1292(13.7)$ & $848(7.7)$ & $<0.001$ & $1237(13.0)$ & $903(8.2)$ & $<0.001$ \\
\hline
\end{tabular}

All values are $n(\%)$ unless otherwise stated.

${ }^{*}$ High volume was defined as being in the top quartile of units by number of care days provided to infants born at $\leq 32^{+6}$ weeks gestation. †Continuous variables were tested by $t$ test, categorical variables by $\chi^{2}$ test.

†BPD defined as requirement of supplementary oxygen for at least 28 days postbirth and at 36 weeks postmenstrual age.

§PMA at discharge equal to gestational age at birth plus length of stay in weeks.

BPD, bronchopulmonary dysplasia; NEC, necrotising enterocolitis; PMA, postmenstrual age; ROP, retinopathy of prematurity.

The standard logistic regressions did not reveal a statistically significant difference in the OR of mortality for very preterm infants admitted to tertiary-level care at the hospital of birth compared with their counterparts admitted to non-tertiary-level care. However, when considering only infants born at $\leq 26^{+6}$ weeks gestation, we found a reduction in the OR of neonatal mortality (OR $0.65,95 \%$ CI 0.46 to $0.91, \mathrm{p}=0.012)$, but not any in-hospital mortality.

For infants admitted to a high-volume neonatal unit at the hospital of birth, a reduced OR of neonatal mortality was observed for those born at $\leq 32^{+6}$ weeks gestation (OR $0.73,95 \%$ CI 0.56 to $0.95, \mathrm{p}=0.018$ ) and at $\leq 26^{+6}$ weeks gestation (OR $0.62,95 \%$ CI 0.44 to 0.87 , $\mathrm{p}=0.006$ ), but this was not replicated for infants born at $27^{+0}$ to $32^{+6}$ weeks gestation. Those infants born at $\leq 26^{+6}$ weeks gestation were also at reduced $O R$ of any in-hospital mortality $(0.71,95 \%$ CI 0.52 to 0.97 , $\mathrm{p}=0.033$ ) and increased OR of BPD (OR 1.59, 95\% CI 1.18 to $2.14, \mathrm{p}=0.002)$ compared with their counterparts admitted to a non-high-volume neonatal unit at the hospital of birth. There were no other statistically significant differences observed for the morbidity outcomes.

\section{Instrument validity}

The instruments were strongly correlated with the characteristics of the unit at the hospital of birth; $88.4 \%$ of infants whose nearest neonatal unit was designated level 3 were born in a hospital with a level 3 unit compared with only $22.5 \%$ of infants whose nearest neonatal unit was not designated level 3. Table 3 shows descriptive statistics for the 20554 very preterm infants by the designation and volume of the neonatal unit nearest to the mother's place of residence. After correcting for deprivation, there were no statistically significant differences in the observed covariates.

\section{Instrumental variables logistic regression}

Table 4 shows the estimated ORs using the instrumental variables logistic regressions. We found no significant differences in neonatal mortality between infants admitted to either tertiary or non-tertiary neonatal care at the hospital of birth. We did find an increased OR of treatment for ROP for very preterm infants born at $27^{+0}-32^{+6}$ weeks gestation born in a hospital with a tertiary-level unit (OR 2.17, 95\% CI 1.06 to 4.47, $\mathrm{p}=0.035$ ).

In contrast to the effect of tertiary-level care, admission to a high-volume neonatal unit at the hospital of birth significantly reduced the OR of neonatal mortality (OR $0.70,95 \%$ CI 0.53 to $0.92, \mathrm{p}=0.011$ ) and any in-hospital mortality (OR $0.68,95 \%$ CI 0.54 to 0.85 , $\mathrm{p}=0.001)$ in very preterm infants. These effects were most acute among infants born at $\leq 26^{+6}$ weeks gestation. In terms of morbidity, the only significant effect was found for BPD (OR 1.78, 95\% CI 1.12 to 2.81, $\mathrm{p}=0.014$ ) for infants born at $\leq 26^{+6}$ weeks gestation and admitted to high-volume neonatal care at the hospital of birth.

\section{Sensitivity analyses}

The results from the sensitivity analyses are presented in online supplementary appendix B. There were 1172 (5.7\%) infants with missing data for antenatal steroids; there were no missing values for the other covariates. The results remained qualitatively similar when all 
Table 2 Adjusted ORs for outcomes associated with admission to either tertiary or high-volume neonatal care at the hospital of birth using a 'standard' logistic regression model

\begin{tabular}{|c|c|c|c|c|c|c|}
\hline \multirow[b]{2}{*}{ Outcome } & \multicolumn{3}{|l|}{ Tertiary neonatal unit } & \multicolumn{3}{|c|}{ High-volume neonatal unit† } \\
\hline & $\begin{array}{l}(1) \\
\leq 32^{+6} \text { weeks }\end{array}$ & $\begin{array}{l}(2) \\
\leq 26^{+6} \text { weeks }\end{array}$ & $\begin{array}{l}\text { (3) } \\
27^{+0}-32^{+6} \text { weeks }\end{array}$ & $\begin{array}{l}\text { (4) } \\
\leq 32^{+6} \text { weeks }\end{array}$ & $\begin{array}{l}\text { (5) } \\
\leq 26^{+6} \text { weeks }\end{array}$ & $\begin{array}{l}(6) \\
27^{+0}-32^{+6} \text { weeks }\end{array}$ \\
\hline Neonatal m & 0.77 (0.59 to 1.00$)$ & $0.65^{\star}(0.46$ to 0.91$)$ & 0.92 (0.69 to 1.22$)$ & $0.73^{*}(0.56$ to 0.95$)$ & $0.62^{* *}(0.44$ to 0.87$)$ & $0.86(0.65$ to 1.14$)$ \\
\hline Any in-hospital mortality & $0.91(0.72$ to 1.15$)$ & 0.78 (0.57 to 1.06$)$ & 1.06 (0.83 to 1.36$)$ & $0.83(0.65$ to 1.05$)$ & $0.71^{*}(0.52$ to 0.97$)$ & $0.96(0.75$ to 1.24$)$ \\
\hline BPD & $1.23^{* \star}(1.07$ to 1.40$)$ & $1.50^{\star \star}(1.11$ to 2.01$)$ & 1.17 (0.99 to 1.39$)$ & 1.11 (0.97 to 1.28$)$ & $1.59^{* *}(1.18$ to 2.14$)$ & 1.02 (0.86 to 1.22$)$ \\
\hline Treatment for ROP & $1.26(0.91$ to 1.75$)$ & 1.09 (0.76 to 1.57$)$ & 1.52 (0.91 to 2.55$)$ & 0.95 (0.68 to 1.32$)$ & 0.81 (0.56 to 1.17$)$ & $1.22(0.71$ to 2.09$)$ \\
\hline Surgery for NEC & 1.05 (0.76 to 1.44$)$ & 0.89 (0.58 to 1.36$)$ & 1.17 (0.80 to 1.70$)$ & $1.05(0.76$ to 1.45$)$ & 0.94 (0.62 to 1.45$)$ & $1.11(0.76$ to 1.61$)$ \\
\hline PMA at discharge $>40$ weeks & $1.17(0.97$ to 1.41$)$ & 1.09 (0.87 to 1.37$)$ & 1.19 (0.97 to 1.47$)$ & $1.13(0.94$ to 1.37$)$ & 1.11 (0.89 to 1.38$)$ & 1.11 (0.90 to 1.37$)$ \\
\hline
\end{tabular}

Values are ORs $(95 \% \mathrm{Cl})$.

Models are adjusted for gestational age, gestational age squared, birthweight z-score, use of antenatal steroids, gender, infant year of birth and deprivation.

${ }^{*} \mathrm{p}<0.05,{ }^{\star *} \mathrm{p}<0.01,{ }^{* * *} \mathrm{p}<0.001$.

†High volume was defined as being in the top quartile of units by number of care days provided to infants born at $\leq 32^{+6}$ weeks gestation.

BPD, bronchopulmonary dysplasia; NEC, necrotising enterocolitis; PMA, postmenstrual age; ROP, retinopathy of prematurity.

Table 3 Descriptive statistics for the sample of preterm infants born $\leq 32^{+6}$ weeks gestation by designation of the neonatal unit nearest to maternal place of residence

Unit level designation Unit volume

\begin{tabular}{|c|c|c|c|c|c|c|c|}
\hline $\begin{array}{l}\text { Nearest unit } \\
\text { tertiary level }\end{array}$ & $\begin{array}{l}\text { Nearest unit } \\
\text { non-tertiary } \\
\text { level }\end{array}$ & p Valuet & $\begin{array}{l}\text { p Value } \neq, \\
\text { controlling for } \\
\text { deprivation }\end{array}$ & $\begin{array}{l}\text { Nearest unit } \\
\text { high volume }\end{array}$ & $\begin{array}{l}\text { Nearest unit } \\
\text { non-high } \\
\text { volume }\end{array}$ & p Valuet & $\begin{array}{l}\text { p Valuef, } \\
\text { controlling } \\
\text { for deprivation }\end{array}$ \\
\hline 7167 (34.9) & $13387(65.1)$ & & & 7357 (35.8) & $13197(64.2)$ & & \\
\hline $29.6(2.4)$ & 29.7 (2.3) & 0.040 & 0.418 & $29.6(2.4)$ & $29.6(2.3)$ & 0.181 & 0.526 \\
\hline $1377.4(429.2)$ & $1394.2(424.5)$ & 0.007 & 0.262 & $1376.7(426.7)$ & $1394.8(425.7)$ & 0.004 & 0.111 \\
\hline $4703(65.6)$ & 8953 (66.9) & 0.069 & 0.584 & 4749 (64.6) & 8907 (67.5) & $<0.001$ & 0.052 \\
\hline $1751(24.4)$ & $1611(12.0)$ & $<0.001$ & NA & $1476(20.1)$ & 1886 (14.3) & $<0.001$ & NA \\
\hline 3820 (53.3) & 7165 (53.5) & 0.761 & 0.854 & 3958 (53.8) & 7027 (53.3) & 0.447 & 0.378 \\
\hline 4753 (88.4) & 2290 (22.5) & $<0.001$ & $<0.001$ & 3839 (69.5) & 3204 (31.9) & $<0.001$ & $<0.001$ \\
\hline 3703 (68.9) & 3374 (33.1) & $<0.001$ & $<0.001$ & 4764 (86.3) & $2313(23.0)$ & $<0.001$ & $<0.001$ \\
\hline
\end{tabular}

n (\%)

Gestation (weeks), mean (SD)

Birth weight (g), mean (SD)

Received full or partial course of antenatal

steroids

Deprivation score bottom $10 \%$

Male

Birth in hospital with tertiary-level unit

Birth in hospital with high-volume unit

$3703(68.9)$

All values are $n(\%)$ and are a proportion of the column total unless otherwise stated.
${ }^{*}$ High volume was defined as being in the top quartile of units by number of care days provided to infants born at $\leq 32^{+6}$ weeks gestation.

*High volume was defined as being in the top quartile of units by number of
†Continuous variables were tested by $t$ test, categorical variables by $\chi^{2}$ test.

$\mathrm{fp}$ Value of F-test of coefficient on instrument from a regression of variable of interest on instrument and deprivation indicator. 


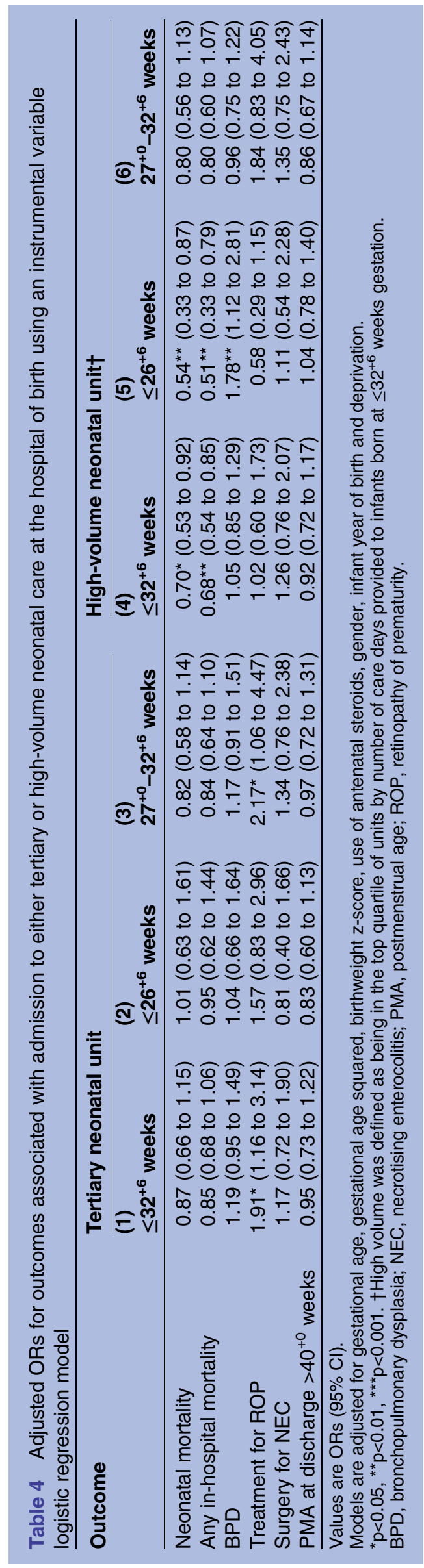

infants with any missing data were excluded from the analyses (see online supplementary table B1).

The results remained robust to the inclusion of unit level random effects. We further excluded infants who died from analyses of the morbidity outcomes. This did not reveal any evidence of differences in the ORs except for the OR of treatment for ROP for infants admitted to tertiary-level care at the hospital of birth (OR 1.96, 95\% CI 1.15 to $3.32, \mathrm{p}=0.013$; see online supplementary table B2). No evidence of an effect for the outcome defined as any in-hospital mortality and/or BPD was observed (see online supplementary table B2). Three alternative measures of volume were also used. In these sensitivity analyses, the OR of any in-hospital mortality remained significantly lower for very preterm infants admitted to a high-volume unit at the hospital of birth (see online supplementary tables B3 and B4). Only eight hospitals $(4.8 \%)$ met the criteria of at least 100 VLBW infants per annum in any of the study years so that only a small proportion $(6.5 \%)$ of the sample was inborn and admitted to these units. There is therefore imprecision around these results with wide CIs; among these infants, the OR of any in-hospital mortality was significantly lower but not statistically significant (see online supplementary table B4).

\section{DISCUSSION}

We examined the effects of designation and volume of neonatal care provided at the hospital of birth on mortality and morbidity outcomes for very preterm infants in England. Our key finding was a consistent reduction in the OR of mortality for very preterm infants admitted to high-volume neonatal units. We examined infants born at $\leq 26^{+6}$ weeks gestation and those born at $27^{+6}$ $32^{+6}$ weeks gestation separately to reflect transfer policies and found a statistically significant reduction in the OR of mortality in the former group only. Furthermore, we found differences in the OR of mortality outcomes between standard logistic regressions and our preferred instrumental variables approach. The standard logistic regressions were generally found to underestimate the beneficial effects of high-volume care on mortality outcomes. This was expected given the aim of MCNs to transfer high-risk infants to high-volume and designation units. With regards to morbidity outcomes, treatment for ROP was the only morbidity for which a statistically significant effect was observed across analyses. We found that infants born at $27^{+6}-32^{+6}$ weeks gestation in hospitals with tertiary-level units were at increased OR of receiving treatment for ROP; however, only a very small number of these infants received treatment for ROP $(86 / 17995 ; 0.5 \%)$, suggesting the observed difference may not be clinically significant.

Our preferred instrumental variables methodology, in the absence of a randomised assignment of infants to units, enabled us to estimate the causal effects of designation and volume of neonatal care provided at the 
hospital of birth using observational data. This approach has been widely applied in other healthcare evaluations. ${ }^{26}$ However, we can only identify one previous application of this methodology to the evaluation of perinatal outcomes. ${ }^{7}$ Our findings agree with the findings of a US-based study that examined the separate effects of level and volume of neonatal care. ${ }^{4}$ We also found a reduction in the OR of mortality when analysing the annual number of VLBW admissions of inborn infants-a measure frequently used in US studies of this nature. $^{2}$

We acknowledge limitations to our study. First, instrumental variables methodology only identifies the effect of an intervention or treatment for those individuals whose assignment to treatment is altered by the instrumental variable. ${ }^{27}$ We do not know the effects for infants who would always be born in hospitals with a high-level or high-volume neonatal unit despite the location of the mother's residence (see online supplementary appendix A). Nevertheless, we demonstrated the validity of our instruments in meeting the required assumptions. Importantly, the assumptions required for an instrumental variables methodology are weaker than those required to support a 'standard' analysis, which requires that infants are randomly assigned to hospitals of birth; otherwise the estimated ORs will be biased. Second, due to data limitations we cannot control for the effects of care and risk of death in the delivery suite at the hospital of birth. However, high-volume delivery units have been shown to be associated with a reduced risk of neonatal mortality. ${ }^{28}{ }^{29}$ Since high-volume delivery units are often found in hospitals with high-volume neonatal care this would lead us to suspect that our analyses underestimate the benefits of birth in hospitals with high-volume neonatal care.

Third, we are unable to disentangle the effects of the unit at the place of birth and subsequent transfers on final outcomes. We therefore cannot assess whether increasing the provision of transfers attenuates the increased OR of mortality associated with birth in hospitals without high-volume neonatal care. While identification of acute neonatal transfers was possible from our data, identifying the effects of transfer on outcomes presents a number of difficult statistical issues. However, we expect that, if transfers to high-volume units reduce the OR of mortality, our effects presented in this paper underestimate the benefit of birth in a hospital with high-level or high-volume neonatal care (see online supplementary appendix A for an extended discussion), although neonatal transport itself may have negative effects on infant health outcomes. ${ }^{30} 31$ A final limitation is that a small number of neonatal units in England $(n=8)$ across MCNs do not contribute data to the NNRD and/or participate in NESCOP. The effect of also including data from these units on outcomes remains a topic for future enquiry.

An intervention that increases the proportion of very preterm infants born in hospitals with high-volume neonatal units may involve increasing the proportion of in utero transfers. Transfers of women prior to delivery are generally preferable because they are believed to be safer and less expensive than postnatal transfers of vulnerable infants. ${ }^{32}$ However, a study in 2009 showed that almost one-half of all in utero transfer requests to the London Ambulance Service were unsuccessful for nonclinical reasons. ${ }^{33}$ Furthermore, studies from other countries, including Portugal, Finland and the USA, have shown that in more regionalised systems as many as 90 $95 \%$ of very preterm or VLBW infants are born in hospitals with tertiary designation neonatal units. ${ }^{10} 3435$ The effects of transfers within different organisational structures for neonatal care remains an important area for future research especially as the new English Operational Delivery Networks will supersede the perinatal MCNs as part of the changes following the Health and Social Care Act (2012) ${ }^{36}$

In conclusion, instrumental variables methodology did not reveal evidence of a difference in mortality outcomes between very preterm infants admitted to either tertiary or non-tertiary neonatal care at the hospital of birth. However, we do provide evidence of reduced OR of mortality for very preterm infants admitted to highvolume neonatal units at delivery hospitals. The effect of volume on neonatal outcomes is an important consideration for policy makers deciding the optimal organisation of neonatal specialist services.

\section{Author affiliations}

${ }^{1}$ Warwick Medical School, University of Warwick, Coventry, UK ${ }^{2}$ Department of Economics, University of Warwick, Coventry, UK ${ }^{3}$ Academic Neonatology, UCL Institute for Women's Health, London, UK ${ }^{4}$ Department of Health Sciences, University of Leicester, Leicester, UK ${ }^{5}$ Section of Neonatal Medicine, Department of Medicine, Chelsea and Westminster Campus, Imperial College London, London, UK

Acknowledgements The authors would like to thank Nicola Fitz-Simon for invaluable advice on statistical issues and Eugene Statnikov and Daniel Gray for assistance with the data. They thank the staff from neonatal units involved in capturing electronic data and Richard Colquhoun, Neonatal Data Analysis Unit manager, and Surbhi Shah for administrative support. They also thank Andy Cole, Kate Bennett, Helen Kirrane and the Steering Board of the Neonatal Data Analysis Unit. They also thank the following contributing neonatal units and clinical leads (all units were included in the NESCOP survey and offered an 'opt out' of service evaluation that made use of NNRD data): Matthew Babirecki, Airedale General Hospital; Andrew Gallagher, Alexandra Hospital; D Manning, Arrowe Park Hospital; Tim Wickham, Barnet Hospital; MA Saeed, Barnsley District General Hospital; Nawfal Sharief, Basildon Hospital; Ruth Wigfield, Basingstoke and North Hampshire Hospital; Nigel Brooke, Bassetlaw District General Hospital; Raghavan Kadalraja, Bedford Hospital; Julie Nycyk, Birmingham City Hospital; Mike Watkinson, Birmingham Heartlands Hospital; Imogen Morgan, Birmingham Women's Hospital; Sam Oddie, Bradford Royal Infirmary; R N Mahesh Babu, Broomfield Hospital; Eleri Crosbie, Calderdale Royal Hospital; Tim Wickham, Chase Farm Hospital; Gary Hartnoll, Chelsea and Westminster Hospital; Aiwyne Foo, Chesterfield Royal Hospital; Sarah Dalton, Colchester General Hospital; Graham Whincup, Conquest Hospital; Stephen Brearey, Countess of Chester Hospital; John Chang, Croydon University Hospital (Mayday); Mahfud Ben-Hamida, Cumberland Infirmary; Abdul Hasib, Darent Valley Hospital; S Subramania Krish Namoorthy, Darlington Memorial Hospital; Julian Larson, Derriford Hospital; Kallinath Shyamannr, Dewsbury and District Hospital; Pauline Adiotomre, Diana Princess of Wales Hospital; Nigel Brooke, Doncaster 
Royal Infirmary; Phil Wylie, Dorset County Hospital; Vivien Chan, Ealing Hospital; K Aboul Khader, East Surrey Hospital; Graham Whincup, Eastbourne District General Hospital; Ruth Shephard, Epsom General Hospital; Sri Nagesh Panasa, Fairfield general; J P Wyllie, Friarage Hospital; Abdus Mallik, Frimley Park Hospital; Owen Galt, Furness General Hospital; R C de Boer, George Eliot Hospital; Jennifer Holman, Gloucestershire Royal Hospital; Mike Watkinson, Good Hope Hospital; Stanley Zengeya, Great Western Hospital; Morag Campbell, Guy's and St Thomas' Hospital; D Gillies, Harrogate District Hospital; Andrew Butterfill, Hereford County Hospital; Michele Cruwys, Hillingdon Hospital; Hilary Dixon, Hinchingbrooke Hospital; Kate Costeloe, Homerton Hospital; Eleri Adams, Horton Hospital; Chris Wood, Hull Royal Infirmary; Matthew James, Ipswich Hospital; J P Wyllie, James Cook University Hospital; Vasantha Jayalal, James Paget Hospital; Eleri Adams, John Radcliffe Hospital; Pratibha Rao, Kettering General Hospital; B K Sharma, King George Hospital; Abhi Gkeenga, King's College Hospital; Vibert Noble, King's Mill Hospital; Dwight Lindo, Kingston Hospital; Meera Lama, Lancashire Women and Newborn Centre; Lawrence Miall, Leeds Neonatal Service; Andrew Currie, Leicester General Hospital; Andrew Currie, Leicester Royal Infirmary; A Thirumurugan, Leighton Hospital; Sudhakar Rao, Lincoln County Hospital; Andy Raffles, Lister Hospital; C W Yoxall, Liverpool Women's Hospital; P Sivakumar, Luton and Dunstable Hospital; Ignatios Losa, Macclesfield District General Hospital; Hamudi Kisat, Maidstone; B Jan Muhamad, Manor Hospital; Aung Soe, Medway Maritime Hospital; Jasper Katumba, Milton Keynes Foundation Trust Hospital; Babu Kumararatne, New Cross Hospital; Vimala Gopinathan, Newham General Hospital; Mark Dyke, Norfolk and Norwich University Hospital; Yonas Cherinet, North Devon District Hospital; Sri Nagesh Panasa, North Manchester General Hospital; Lesley Alsford, North Middlesex University Hospital; Fiona Thompson, Northampton General Hospital; Paul Mannx, Northwick Park Hospital; Stephen Wardle, Nottingham City Hospital; Stephen Wardle, Nottingham University Hospital; Tim McBride, Ormskirk District General Hospital; Seif Babiker, Peterborough City Hospital; Sudhakar Rao, Pilgrim Hospital; Minesh Khashu, Poole Hospital NHS Foundation Trust; Than Soe, Princess Alexandra Hospital; Mike Hall, Princess Anne Hospital; Philip Amess, Princess Royal Hospital; Shaun Walter, Princess Royal University Hospital; Andy Raffles, Queen Elizabeth II Hospital; C R Groves, Queen Alexandra Hospital; Lidia Tyszczuk, Queen Charlotte's Hospital; Susan Rubin, Queen Elizabeth Hospital; Shaun Walter, Queen Elizabeth Hospital; Dennis Bosman, Queen Elizabeth Hospital (Gateshead); David Long, Queen Elizabeth the Queen Mother Hospital; Azhar Manzoor, Queen's Hospital; B K Sharma, Queen's Hospital; Amanda Ogilvy-Stuart, Rosie Maternity Hospital; Christine Harrison, Rotherham District General Hospital; Vibha Sharma, Royal Albert Edward Infirmary; G J Boson, Royal Berkshire Hospital; M Yadan, Royal Bolton Hospital; Paul Munyard, Royal Cornwall Hospital; John McIntyre, Royal Derby Hospital; Vaughan Lewis, Royal Devon and Exeter Hospital; D Schapira, Royal Hampshire County Hospital; Owen Galt, Royal Lancaster Infirmary; Natasha Maddock, Royal Oldham Hospital; Richa Gupta, Royal Preston Hospital; Alison Moore, Royal Shrewsbury Hospital; Charles Godden, Royal Surrey County Hospital; Philip Amess, Royal Sussex County Hospital; Steve Jones, Royal United Hospital; Alan Fenton, Royal Victoria Infirmary; Anande Mohite, Russells Hall Hospital; Jonathan Moise, Salford Royal; Shirley Kinsey, Salisbury District Hospital; Mazen Qunibi, Scarborough General Hospital; Pauline Adiotomre, Scunthorpe General Hospital; Rob Bolton, South Tyneside District Hospital; Arfa Khan, Southend Hospital; Richard Wach, Southmead Hospital; Sandra Calvert, St George's Hospital; Ruth Shephard, St Helier Hospital; Anthony Emmerson, St Mary's Hospital; Peter Chow, St Mary's Hospital; Sian Butterworth, St Mary's Hospital; James Tooley, St Michael's Hospital; Peter Reynolds, St Peter's Hospital; Avril Garg, St Richard's Hospital; K K Tewary, Staffordshire General Hospital; Carrie Heal, Stepping Hill Hospital; Gail Whitehead, Stoke Mandeville Hospital; Majd Abu-Hard, Sunderland Royal Hospital; Jacqueline Birch, Tameside General Hospital; Rebecca Mann, Taunton and Somerset Hospital; Elizabeth Pilling, The Jessop Wing; Vivienne van Someren, The Royal Free Hospital; Rainer Ebel, The Royal London Hospital; Stefan Schulee, Torbay Hospital; Hamudi Kisat, Tunbridge Wells Hospital; Mark Sellwood, University College Hospital; Kate Blake, University Hospital Coventry; Jauro Kuna, University Hospital Lewisham; S Subramania Krish Namoorthy, University Hospital of North Durham; Kate Palmer, University Hospital of North Staffordshire; Ian Verber, University Hospital of North Tees; Faisal Al-Zidgali, University Hospital of South Manchester; A J Rowlands, Victoria Hospital;
Joan Oliver, Wansbeck General Hospital; Delyth Webb, Warrington Hospital; R B Acharya, Warwick Hospital; Chaniyil A Ramesh, Watford General Hospital; Mahfud Ben-Hamida, West Cumberland Hospital; Hashir Ariff, West Middlesex University Hospital; Ian Evans, West Suffolk Hospital; Rekha Sanghavi, Wexham Park Hospital; Caroline Sullivan, Whipps Cross University Hospital; Laweh Amegavie, Whiston Hospital; ER Broadhurd, Whittington Hospital; David Long, William Harvey Hospital; Andrew Gallagher, Worcestershire Royal Hospital; Anil Garg, Worthing Hospital; Megan Eaton, Yeovil District Hospital; Guy Millman, York District Hospital.

Contributors SIW conceived the study. SIW, WA and SP contributed to developing the econometric methodology for the study. SIW prepared the data for analysis. SIW, WA, SP, NMa, ASM, ESD and NMo contributed to covariate selection and interpretation of the results. SS managed the extraction and cleaning of NNRD variables. SIW prepared the first draft of the paper; this and all subsequent drafts were reviewed and revised by all authors. All authors approved the final version submitted.

Funding The Neonatal Data Analysis Unit is supported in part by a Programme Grant for Applied Research (RP-PG-0707-10010) from the National Institute of Health Research (NIHR) and unrestricted funding from the Department of Health, Danone, AbbVie and Abbott International.

Competing interests SIW receives funding from Bliss and the Department of Economics, University of Warwick. NMa receives part funding from the Department of Health's NIHR Biomedical Research Centre's funding scheme at UCLH/UCL. Bliss also provides funding for the NESCOP group.

Ethics approval This study was carried out with the National Neonatal Research Database (REC 10/H0803/151) as part of NESCOP undertaken with permission from NHS Trust Caldicott Guardian.

Provenance and peer review Not commissioned; externally peer reviewed.

Data sharing statement Statistical code is available from the corresponding author.

Open Access This is an Open Access article distributed in accordance with the Creative Commons Attribution Non Commercial (CC BY-NC 3.0) license, which permits others to distribute, remix, adapt, build upon this work noncommercially, and license their derivative works on different terms, provided the original work is properly cited and the use is non-commercial. See: http:// creativecommons.org/licenses/by-nc/3.0/

\section{REFERENCES}

1. Lasswell SM, Barfield WD, Rochat RW, et al. Perinatal regionalization for very low-birth-weight and very preterm infants: a meta-analysis. JAMA 2010;304:992-1000

2. Phibbs CS, Baker LC, Caughey $A B$, et al. Level and volume of neonatal intensive care and mortality in very-low-birth-weight infants. N Engl J Med 2007;356:2165-75.

3. Cifuentes J, Bronstein J, Phibbs CS, et al. Mortality in low birth weight infants according to level of neonatal care at hospital of birth. Pediatrics 2002;109:745-51.

4. Chung JH, Phibbs CS, Boscardin WJ, et al. The effect of neonatal intensive care level and hospital volume on mortality of very low birth weight infants. Med Care 2010;48:635-44.

5. Rogowski JA, Horbar JD, Staiger DO, et al. Indirect vs direct hospita quality indicators for very low-birth-weight infants. JAMA 2004;291:202-9.

6. Bartels DB, Wypij D, Wenzlaff $P$, et al. Hospital volume and neonatal mortality among very low birth weight infants. Pediatrics 2006;117:2206-14.

7. Lorch SA, Baiocchi M, Ahlberg CE, et al. The differential impact of delivery hospital on the outcomes of premature infants. Pediatrics 2012;130:270-8.

8. Fellman V, Hellström-Westas L, Norman M, et al. One-year survival of extremely preterm infants after active perinatal care in Sweden. JAMA 2009;301:2225-33.

9. Johansson S, Montgomery SM, Ekbom A, et al. Preterm delivery, level of care, and infant death in Sweden: a population-based study. Pediatrics 2004;113:1230-5.

10. Rautava L, Lehtonen L, Peltola M, et al. The effect of birth in secondary- or tertiary-level hospitals in Finland on mortality in very preterm infants: a birth-register study. Pediatrics 2007;119:e257-63. 
11. Synnes AR, Macnab YC, Qiu Z, et al. Neonatal intensive care unit characteristics affect the incidence of severe intraventricular hemorrhage. Med Care 2006;44:754-9.

12. Phibbs CS. Managed clinical networks in neonatal care. BMJ 2012;344:e2423.

13. Department of Health. Report of Department of Health Working Group on Neonatal Intensive Care Services. London, 2003.

14. Gale C, Santhakumaran S, Nagarajan S, et al. Impact of managed clinical networks on NHS specialist neonatal services in England: population based study. BMJ 2012;344:e2105.

15. Tucker J. Patient volume, staffing, and workload in relation to risk-adjusted outcomes in a random stratified sample of UK neonatal intensive care units: a prospective evaluation. Lancet 2002;359:99-107.

16. Hamilton KESC, Redshaw ME, Tarnow-Mordi W. Nurse staffing in relation to risk-adjusted mortality in neonatal care. Arch Dis Child Fetal Neonatal Ed 2007;92:F99-103.

17. Van Reempts P, Gortner L, Milligan D, et al. Characteristics of neonatal units that care for very preterm infants in Europe: results from the MOSAIC study. Pediatrics 2007;120:e815-25.

18. Department of Health. Reforming NHS financial flows: introducing payment by results. London. 2002.

19. Ehrenkranz RA, Walsh MC, Vohr BR, et al. Validation of the National Institutes of Health consensus definition of bronchopulmonary dysplasia. Pediatrics 2005;116:1353-60.

20. Medlock S, Ravelli ACJ, Tamminga $P$, et al. Prediction of mortality in very premature infants: a systematic review of prediction models. PLOS ONE 2011;6:e23441.

21. Noble M, McLennan D, Wilkinson K, et al. English Indices of Deprivation 2007. Communities and Local Government, London. 2008.

22. British Association of Perinatal Medicine. Categories of care. 2011 http://www.bapm.org/publications/documents/guidelines/ CatsofcarereportAug11.pdf (accessed 12 Jun 2012).

23. Office for National Statistics. Super output areas. 2011. http://www. ons.gov.uk/ons/guide-method/geography/beginner-s-guide/census/ super-output-areas--soas-/index.html (accessed 12 Feb 2013).
24. Smith LK, Draper ES, Manktelow BN, et al. Socioeconomic inequalities in very preterm birth rates. Arch Dis Child Fetal Neonatal Ed 2007;92:F11-14.

25. Terza JV, Basu A, Rathouz PJ. Two-stage residual inclusion estimation: addressing endogeneity in health econometric modeling. $J$ Health Econ 2008;27:531-43.

26. Tsai AC, Votruba M, Bridges JFP, et al. Overcoming bias in estimating the volume-outcome relationship. Health Serv Res 2006;41:252-64.

27. Imbens $\mathrm{G}$, Angrist J. Identification and estimation of local average treatment effects. Econometrica 1994;62:467-75.

28. Heller G, Richardson DK, Schnell R, et al. Are we regionalized enough? Early-neonatal deaths in low-risk births by the size of delivery units in Hesse, Germany 1990-1999. Int J Epidemiol 2002;31:1061-8.

29. Moster D, Lie RT, Markestad T. Relation between size of delivery unit and neonatal death in low risk deliveries: population based study. Arch Dis Child Fetal Neonatal Ed 1999;80:F221-5.

30. Bowman E, Doyle LW, Murton LJ, et al. Increased mortality of preterm infants transferred between tertiary perinatal centres. BMJ 1988;297:1098-100.

31. Lee SK, Zupancic JA, Pendray M, et al. Transport risk index of physiologic stability: a practical system for assessing infant transport care. J Pediatr 2001;139:220-6.

32. Mistry H, Dowie R, Franklin RCG, et al. Costs of neonatal care for low-birthweight babies in English hospitals. Acta Paediatr 2009;98:1123-9.

33. Gale C, Hay A, Philipp C, et al. In-utero transfer is too difficult: results from a prospective study. Early Hum Dev 2012;88:147-50.

34. Binder S, Hill K, Meinzen-Derr J, et al. Increasing VLBW deliveries at subspecialty perinatal centers via perinatal outreach. Pediatrics 2011;127:487-93

35. Neto MT. Perinatal care in Portugal: effects of 15 years of a regionalized system. Acta Paediatr 2006;95:1349-52.

36. Delamothe T, Godlee F. Dr Lansley's monster. BMJ 2011; 342:d408. 